\title{
Cinnamaldehyde causes apoptosis of myeloid-derived suppressor cells through the activation of TLR4
}

\author{
WANZHUO HE ${ }^{1 *}$, WENSHENG ZHANG ${ }^{2 *}$, QILIN ZHENG ${ }^{2 *}$, ZHENG WEI $^{2}$, YUANYUAN WANG $^{3}$, \\ MINGHUA HU ${ }^{3}$, FANGLI MA ${ }^{3}$, NING TAO ${ }^{2}$ and $\mathrm{CONG} \mathrm{LUO}^{4}$ \\ ${ }^{1}$ College of Life Sciences, Peking University, Beijing 100871; ${ }^{2}$ Key Laboratory of Protein and Peptide Pharmaceuticals, \\ Institute of Biophysics, Chinese Academy of Sciences, Beijing 100101; ${ }^{3}$ Infinitus Chinese Herbal Immunity Research Centre, \\ Infinitus China Company Ltd., Guangzhou, Guangdong 510663; ${ }^{4}$ Department of Abdominal Oncology, \\ Zhejiang Cancer Hospital, Hangzhou, Zhejiang 310022, P.R. China
}

Received December 24, 2017; Accepted November 16, 2018

DOI: $10.3892 / \mathrm{ol} .2019 .10544$

\begin{abstract}
Malignant tumors are among the most life-threatening diseases in the world. Although many different types of antitumor agents are available, severe side effects and toxicity limit their applications. Myeloid-derived suppressor cells (MDSCs) inhibit the antitumor immune response by suppressing the proliferation of $\mathrm{T}$ cells, the production of cytokines and the killing of tumor cells. As MDSCs have become novel targets in cancer therapy, this research focused on the anti-MDSC function of cinnamaldehyde (CA), which is extracted from cinnamon, a traditional Chinese spice. In the present study, MDSCs isolated from the spleens of mice with colon cancer were used as an in vitro model to assess the efficacy of CA. Treatment of MDSCs with CA significantly decreased cell proliferation and induced apoptotic cell death. Subsequent experiments demonstrated that CA treatment enhanced the expression of Bax and caspase- 9 and inhibited the expression of Bcl-2, suggesting that CA induced apoptosis in the MDSCs via the intrinsic pathway. Taken together, the results demonstrated that CA exhibited significant anti-MDSC activity and attenuated the suppression of the antitumor immune response, indicating a potential use for CA in cancer therapy.
\end{abstract}

Correspondence to: Dr Cong Luo, Department of Abdominal Oncology, Zhejiang Cancer Hospital, 1 East Banshan Road, Gongshu, Hangzhou, Zhejiang 310022, P.R. China

E-mail:1w939291@126.com

Dr Ning Tao, Key Laboratory of Protein and Peptide Pharmaceuticals, Institute of Biophysics, Chinese Academy of Sciences, 15 Datun Road, Beijing 100101, P.R. China

E-mail: tao@ibp.ac.cn

*Contributed equally

Key words: cinnamaldehyde, antitumor, myeloid-derived suppressor cells, apoptosis, toll-like receptor 4

\section{Introduction}

Myeloid-derived suppressor cells (MDSCs) are a heterogeneous population of cells that serve an important role in the negative regulation of the immune response during cancer, inflammation and infection (1). With high levels of arginase I and inducible nitric oxide synthase (iNOS), MDSCs suppress T-cell function through the inhibition of Janus kinase 3 and signal transducer and activator of transcription 5 functions in T-cells (2), the inhibition of major histocompatibility complex (MHC) II expression (3) and the induction of T-cell apoptosis (4).

As the mechanisms of immune suppression by MDSCs have been discovered, various drugs and biologic inhibitors aimed at MDSCs have also been investigated (5), including ATRA, catalase, fluorouracil and L-N6-(1-Iminoethyl)lysine dihydrochloride $(6,7)$. Cinnamaldehyde (CA) is a bioactive compound isolated from the stem bark of Cinnamomum cassia, and has been used as a Traditional Chinese Medicine (TCM) (8). Studies have demonstrated that $\mathrm{CA}$ exhibits various biological functions, including antibacterial, immunomodulatory, cytotoxic and antiangiogenic activities (9-11). It is also known to have marked antitumor effects in vitro and in vivo through enhancing proapoptotic activity via anti-topoisomerase I and II, or inhibiting NF- $\mathrm{B}$ and activating protein 1 (12-14). However, it has yet to be proven whether CA can reduce immunological suppression induced by malignant tumors, especially those mediated by MDSCs.

The present study assessed the effect of CA on MDSCs and the relative molecular mechanism. This may be useful to provide support for $\mathrm{CA}$ as a promising therapeutic compound for treating or preventing cancer through regulation of the tumor microenvironment.

\section{Materials and methods}

Drugs. CA was purchased from the National Institute for Food and Drug Control (Beijing, China). Dimethyl sulfoxide (DMSO) was purchased from Sigma-Aldrich; Merck KGaA (Darmstadt, Germany).

Cell culture. The present study used MSC-2 cells (MDSCs immortalized using a retrovirus encoding the v-myc and 
v-raf oncogenes) were provided by Dr Francois Ghiringhelli, (Department of Medical Oncology, Center GF Leclerc, Dijon, France). CT26 and RAW 264.7 cells (macrophage cell line) were purchased from the American Tissue Culture Collection (ATCC, Manassas, VA, USA). MC38 tumor cells (murine colon adenocarcinoma cell line) were provided by Professor Yangxin Fu (Chinese Academy of Sciences, Beijing). Cell lines were maintained at $37^{\circ} \mathrm{C}$ in a $5 \% \mathrm{CO}_{2}$ humidified chamber in Dulbecco's modified Eagle's medium (DMEM) (HyClone; GE Healthcare Life Sciences, Logan, UT, USA) supplemented with $10 \%$ fetal bovine serum (FBS) (Pan Biotech, Aidenbach, Bavaria, Germany) and $100 \mathrm{U} / \mathrm{ml}$ penicillin/streptomycin.

Mouse tumor models. BALB/c mice ( $\mathrm{n}=32$; age, 6-8 weeks; female; weight, 18-22 g) and C57BL/6 mice ( $\mathrm{n}=20$; age, 6-8 weeks; female; weight, 18-22 g) were purchased from the Weitonglihua Company (Beijing, China). Toll-like receptor $4^{-/}$ $\left(\mathrm{TLR}^{-/-}\right)$mice were purchased from the Model Animal Research Center of Nanjing University (Nanjing, Jiangsu, China). All mice were maintained in a specific pathogen-free environment at $21-25^{\circ} \mathrm{C}$ and $50 \%$ relative humidity, with a $12 \mathrm{~h}$ light/dark cycle at the Institute of Biophysics, Chinese Academy of Sciences (Beijing, China). Three mice were housed in each cage and provided with sterilized food and water. Mice were grouped randomly, with 8 mice in each group, and all protocols were approved by the appropriate authorities. To generate tumor models, $5 \times 10^{5} \mathrm{MC} 38$ tumor cells or CT26 tumor cells (purchased from ATCC) were injected subcutaneously in the flank of TLR4 $4^{-/}$C57BL/6 mice and $\mathrm{BALB} / \mathrm{c}$ wild-type mice, and splenocytes were isolated after 21 days. Animal experiments were conducted in accordance with the Guidelines for the Care and Use of Laboratory Animals of the National Institute of Health, and were approved by the Biological Research Ethics Committee (Institute of Biophysics, Chinese Academy of Sciences). The maximum size that tumors were permitted to grow to was $1,000 \mathrm{~mm}^{3}$.

Splenocyte isolation. Spleens were dipped into $75 \%$ alcohol for $1 \mathrm{sec}$, then dipped into PBS for $5 \mathrm{sec}$. Next, spleens were ground using frosted glass slides in PBS, and filtered through a mesh filter $(150 \mu \mathrm{m})$, centrifuged at $524 \mathrm{x} \mathrm{g}$ for $3 \mathrm{~min}$ at $4^{\circ} \mathrm{C}$. The cell pellets were resuspended in red blood cell lysis buffer (Cowin Biosciences Co., Ltd., Jiangsu, China). After $1 \mathrm{~min}, 5 \mathrm{ml}$ PBS was added, and cells were filtered and centrifuged at $524 \mathrm{x}$ g for $3 \mathrm{~min}$ at $4^{\circ} \mathrm{C}$. The cell pellets were resuspended with PBS with $2 \%$ FBS and prepared for detection.

Cell survival assay (MTT). An MTT assay was used to assess the cell viability of MSC-2 cells and the macrophage RAW264.7 cell line. MSC2 and RAW264.7 were seeded in 96-well culture plates, respectively, at $3 \times 10^{3}$ cells/well. Following exposure to various concentrations (0, 1, 2 and $4 \mu \mathrm{g} / \mathrm{ml}$ ) of CA for $72 \mathrm{~h}$ at $37^{\circ} \mathrm{C}, 10 \mu \mathrm{l} \mathrm{MTT}$ (Sigma-Aldrich; Merck KGaA, Darmstadt, Germany) solution $(5 \mathrm{mg} / \mathrm{ml}$ in PBS) was added to each well, and the plates were incubated for an additional $4 \mathrm{~h}$ at $37^{\circ} \mathrm{C}$ in a $\mathrm{CO}_{2}$ incubator. A total of $100 \mu \mathrm{l}$ formazan lysis solution (5\% 2-methyl-1-propanol, 10\% SDS, $0.012 \mathrm{~mol} / 1 \mathrm{HCl}$ ) was added to each well. Following a $6-\mathrm{h}$ incubation at $37^{\circ} \mathrm{C}$, the absorbance was read at $570 \mathrm{~nm}$ on a microplate reader (Bio-Rad Laboratories, Inc., Hercules, CA, USA).

Apoptosis assay. In brief, splenocytes isolated from BALB/c mice bearing CT26 tumors were cultured in $6-\mathrm{cm}$ plates. Following a 4 -h incubation at $37^{\circ} \mathrm{C}$, adherent cells $\left(8 \times 10^{4}\right.$ cells/well) were seeded into 24 -well plates. Following treatment with serial concentrations of CA for $48 \mathrm{~h}$, the floating and trypsinized adherent cells were harvested via centrifugation at $1,500 \mathrm{x} \mathrm{g}$ for $2 \mathrm{~min}$ at $4^{\circ} \mathrm{C}$. The cell pellets were washed with cold PBS and prepared for detection according to the manufacturer's protocol for an Annexin V-FITC/PI kit (GenStar, Beijing, China). Samples were analyzed with a BD FACSCalibur flow cytometer (BD Biosciences, Franklin Lakes, NJ, USA) and FlowJo 7.6 software (FlowJo LLC, Ashland, OR, USA).

Flow cytometry. MDSCs treated with CA $(0,1,2$ and $4 \mu \mathrm{g} / \mathrm{ml})$ or dimethyl sulfoxide (DMSO) were labeled for immunofluorescence and analyzed by flow cytometry. Antibodies including APC-anti-Gr1 (cat. no. 553129; dilution, 1:200; BD Biosciences) and PE-anti-CD11b (cat. no. 553311; dilution, 1:1,200; BD Biosciences), as markers of MDSCs, from mice bearing CT26 and MC38 tumors, respectively, and APC-Rat IgG1 isotype antibody (cat. no. R20011-11A; dilution, 1:200; Sungene Biotech, Tianjin, China) and PE-Rat IgG1 isotype antibody (cat. no. R20011-09A; dilution, 1:200; Sungene Biotech) were diluted in PBS with $2 \%$ fetal calf serum (Pan Biotech), and incubated for $30 \mathrm{~min}$ on ice. Next, the cells were washed with PBS plus $2 \%$ fetal calf serum twice. The data were analyzed using FlowJo 7.6 (FlowJo LLC).

Western blotting. MSC-2 cells were lysed by RIPA buffer [50 mM Tris- $\mathrm{HCl}$ (pH 7.5), $150 \mathrm{mM} \mathrm{NaCl}, 1.0 \%$ Nonidet P-40, $0.5 \%(\mathrm{w} / \mathrm{v})$ sodium deoxycholate, $0.1 \%(\mathrm{w} / \mathrm{v}) \mathrm{SDS}$, and $1 \mathrm{mM}$ EDTA] supplemented with $100 \mathrm{mM}$ phenylmethylsulfonyl fluoride, $25 \mu \mathrm{g} / \mathrm{ml}$ aprotinin, $1 \mathrm{mM}$ sodium orthovanadate and $50 \mathrm{nM}$ NaF. Total protein was quantified using a bicinchoninic acid assay, and samples (30 $\mu \mathrm{g} / \mathrm{sample})$ were separated via $10 \%$ SDS-PAGE under denaturing conditions and then transferred onto a nitrocellulose membrane (GE Healthcare, Milwaukee, WI, USA) for $1 \mathrm{~h}$ at $100 \mathrm{~V}$. The membranes were blocked with $3 \%$ BSA in PBS-T $(0.1 \%$ Tween-20) for $2 \mathrm{~h}$ at $4^{\circ} \mathrm{C}$ and then incubated overnight at $4{ }^{\circ} \mathrm{C}$ with the following primary antibodies: p53 (cat. no. 2524; dilution, 1:1,000), caspase-3 (cat. no. 9662; dilution, 1:1,000), caspase-9 (cat. no. 9508; dilution, 1:1,000) (Cell Signaling Technology, Inc., Danvers, MA, USA). Following three washes with PBST, the membrane was incubated with HRP-conjugated goat anti-mouse (cat. no. A3683; dilution, 1:5,000) or goat anti-rabbit IgG (cat. no. A6154; dilution, 1:3,000) secondary antibodies (Sigma-Aldrich; Merck KGaA) at room temperature for $1 \mathrm{~h}$. The membrane was washed with PBST five times (5 min/time) and then incubated with a chemiluminescent substrate (Thermo Fisher Scientific, Inc., Waltham, MA, USA) for $3 \mathrm{~min}$ at room temperature. Specific bands were visualized with a chemiluminescence imaging system (Clinx Science Instruments Co., Ltd., Shanghai, China) and analyzed by Clinx software (http://www.clinx.cn). $\beta$-actin (cat. no. 4970S; 

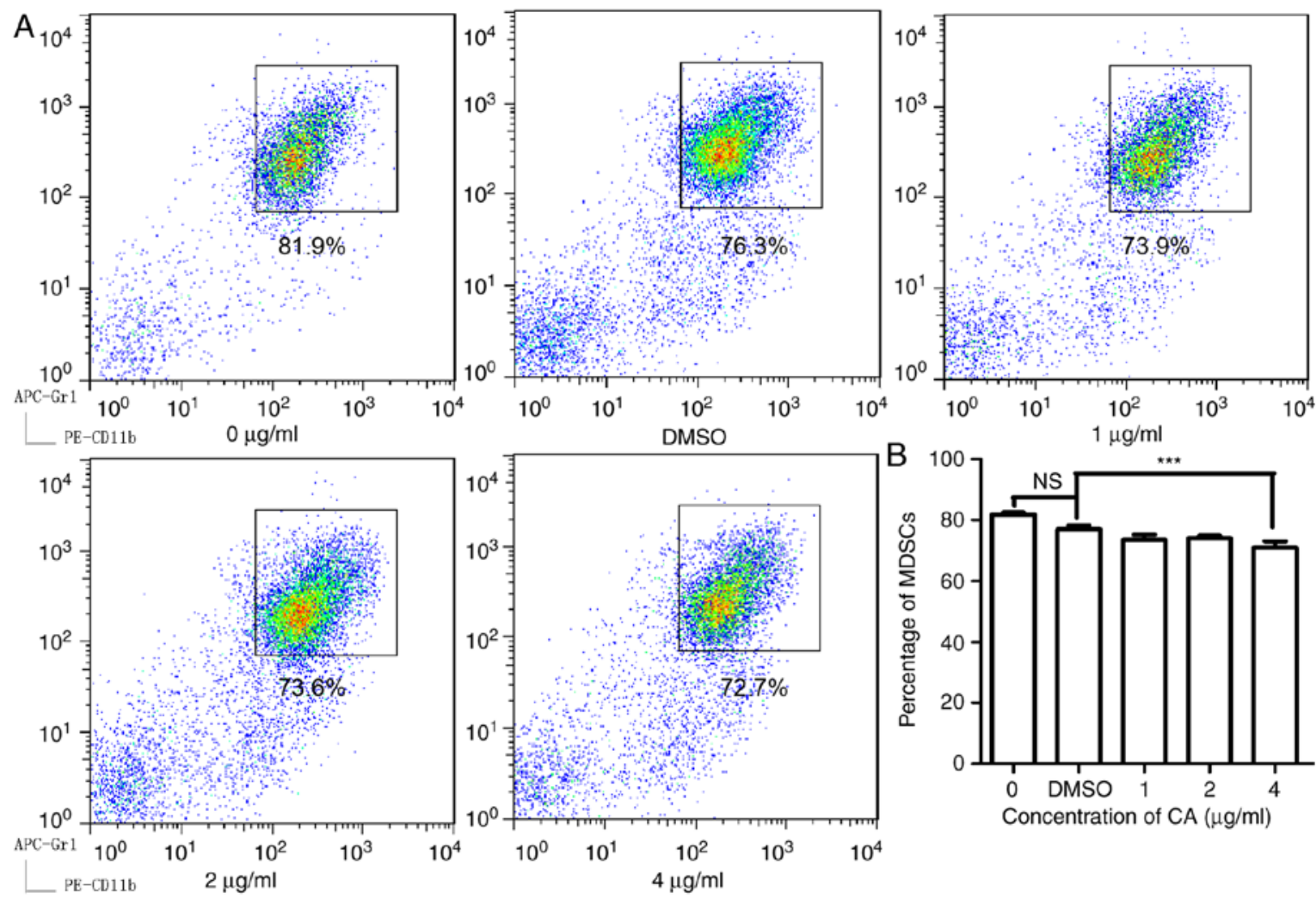

Figure 1. CA decreased the percentage of MDSCs in the spleens of mice bearing CT26 tumors in vitro. The cells isolated from the spleens were seeded in a 96-well microplate $\left(1 \times 10^{6}\right.$ cells/well). (A) Following treatment with different concentrations of CA $(0,1,2$ and $4 \mu \mathrm{g} / \mathrm{ml})$ and DMSO for $36 \mathrm{~h}$, the cells were stained with fluorescent antibodies and subjected to analysis by flow cytometry. (B) The data were analyzed using FlowJo 7.6, and a bar chart was generated with GraphPad Prism 5.0. ${ }^{* * *} \mathrm{P}<0.001$. DMSO, dimethyl sulfoxide; CA, cinnamaldehyde; MDSCs, myeloid-derived suppressor cells; NS, not significant.

dilution, 1:3,000; Cell Signaling Technology, Inc.) was used as an internal standard.

Reverse transcription-quantitative polymerase chain reaction $(R T-q P C R)$. Total RNA was extracted from stimulated MSC-2 cells using TRIzol ${ }^{\circledR}$ reagent (Invitrogen; Thermo Fisher Scientific, Inc.) according to the manufacturer's protocol. cDNA was synthesized using the $5 \mathrm{X}$ All-in-One RT Master mix (Abcam, Cambridge, UK). qPCR was determined using SYBR Green II Mix (Thermo Fisher Scientific, Inc.) on an Applied Biosystems 7500 thermocycler. Primer sequences were as follows: Bax forward, 5'-CCAGGATGCGTCCACCAAG-3' and reverse, 5'-AAGTAGAAGAGGGCAACCAC-3'; caspase-9 forward, 5'-TCCTGGTACATCGAGACCTTG-3' and 5'-AAGTCCCTT TCGCAGAAACAG-3'; caspase-3 forward, 5'-ATGGAGAAC AACAAAACCTCAGT-3' and reverse, 5'-TTGCTCCCATGT ATGGTCTTTAC-3'; caspase-8 forward, 5'-TGCTTGGACTAC ATCCCACAC-3' and reverse, 5'-TGCAGTCTAGGAAGTTGA CCA-3'; p53 forward, 5'-CTCTCCCCCGCAAAAGAAAAA-3' and reverse, 5'-CGGAACATCTCGAAGCGTTTA-3'; and $\beta$-actin forward, 5'-GGAGATTACTGCCCTGGCTCCTA-3' and reverse, 5'-GACTCATCGTACTCCTGCTTGCTG-3'. The housekeeping gene GAPDH was used as an internal control. The thermocycling conditions consisted of an initial denaturation step for $10 \mathrm{~min}$ at $95^{\circ} \mathrm{C}$, then amplification for 40 cycles of $15 \mathrm{sec}$ at $95^{\circ} \mathrm{C}$ and $1 \mathrm{~min}$ at $57^{\circ} \mathrm{C}$. The $\mathrm{qPCR}$ procedure was repeated three times. $\mathrm{qPCR}$ data was analyzed using the $2^{-\Delta \Delta C q}$ method (15).
Statistical analysis. All data are presented as the mean values \pm standard deviation and were evaluated by one-way ANOVA with Tukey's post hoc test. $\mathrm{P}<0.05$ was considered to indicate a statistically significant difference. GraphPad 5.0 (GraphPad Software, Inc., La Jolla, CA, USA) was used for the analysis.

\section{Results}

CA decreases the proportion of MDSCs in splenocytes isolated from mice bearing colon cancer. To examine the effect of CA on MDSCs, isolated splenocytes from mice bearing CT26 tumors and then treated the cells with CA at various concentrations $(0,1,2$ and $4 \mu \mathrm{g} / \mathrm{ml})$ for $24 \mathrm{~h}$. As illustrated in Fig. 1, CA reduced the MDSC $\left(\mathrm{Grl}^{+}, \mathrm{CD} 11 \mathrm{~b}^{+}\right)$numbers in a dose-dependent manner and showed significant suppression at concentrations of $4 \mu \mathrm{g} / \mathrm{ml}(\mathrm{P}<0.05)$.

CA selectively inhibits MSC-2 cell growth. To confirm the inhibition of MDSCs by CA and to examine the toxicity of CA, the viability and growth of the MSC-2 cells and RAW 264.7 cells was assessed using an MTT assay. The viability of MSC-2 cells was significantly reduced $(\mathrm{P}<0.05)$ by CA in a dose-dependent manner (Fig. 2A); however, the viability of RAW 264.7 cells was not reduced by CA (Fig. 2B).

CA induces dose-dependent apoptosis in MDSCs. As CA was demonstrated to markedly reduce the survival of MDSCs, 

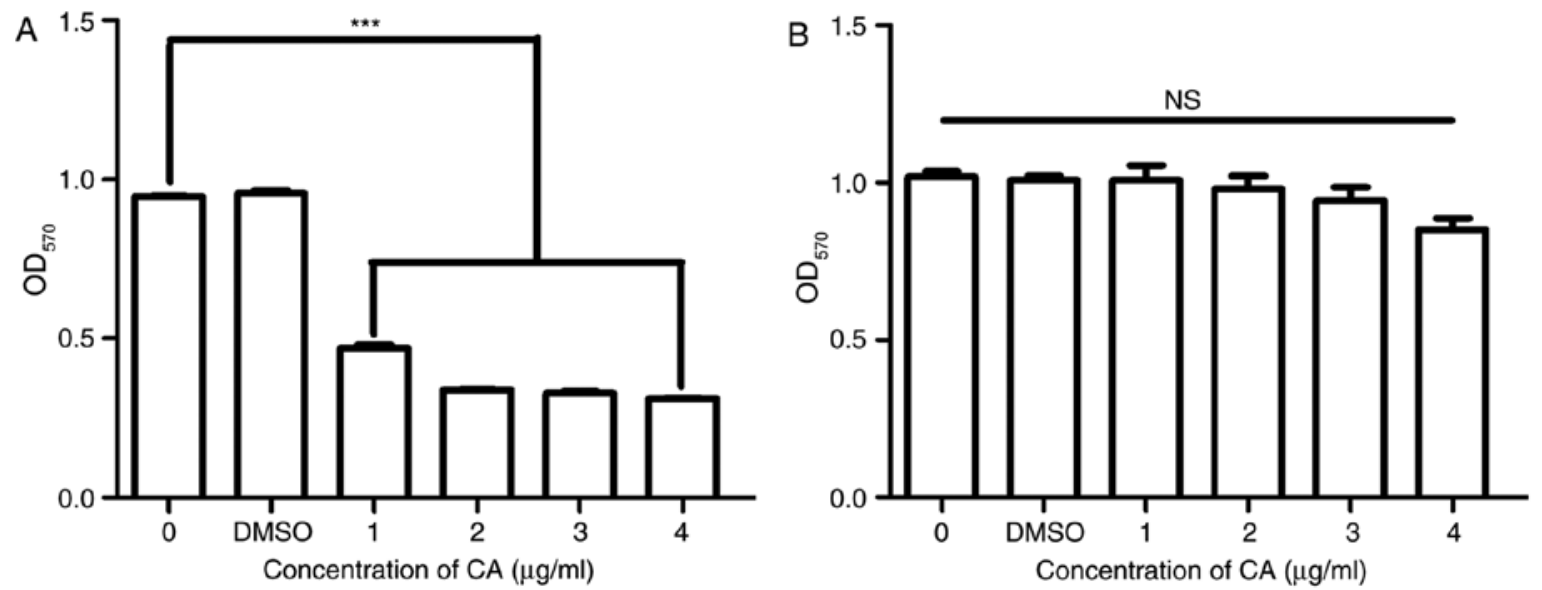

Figure 2. CA inhibited the growth of MSC-2 cells but not macrophages. (A) MSC-2 cells and (B) RAW 264.7 (macrophages) were treated with CA at 0, 1, 2 and $4 \mu \mathrm{g} / \mathrm{ml}$ for $72 \mathrm{~h}$. Cell viability was analyzed by an MTT assay. DMEM without cells was used as the control. ${ }^{* * *} \mathrm{P}<0.001$. CA, cinnamaldehyde; NS, not significant; OD, optical density.
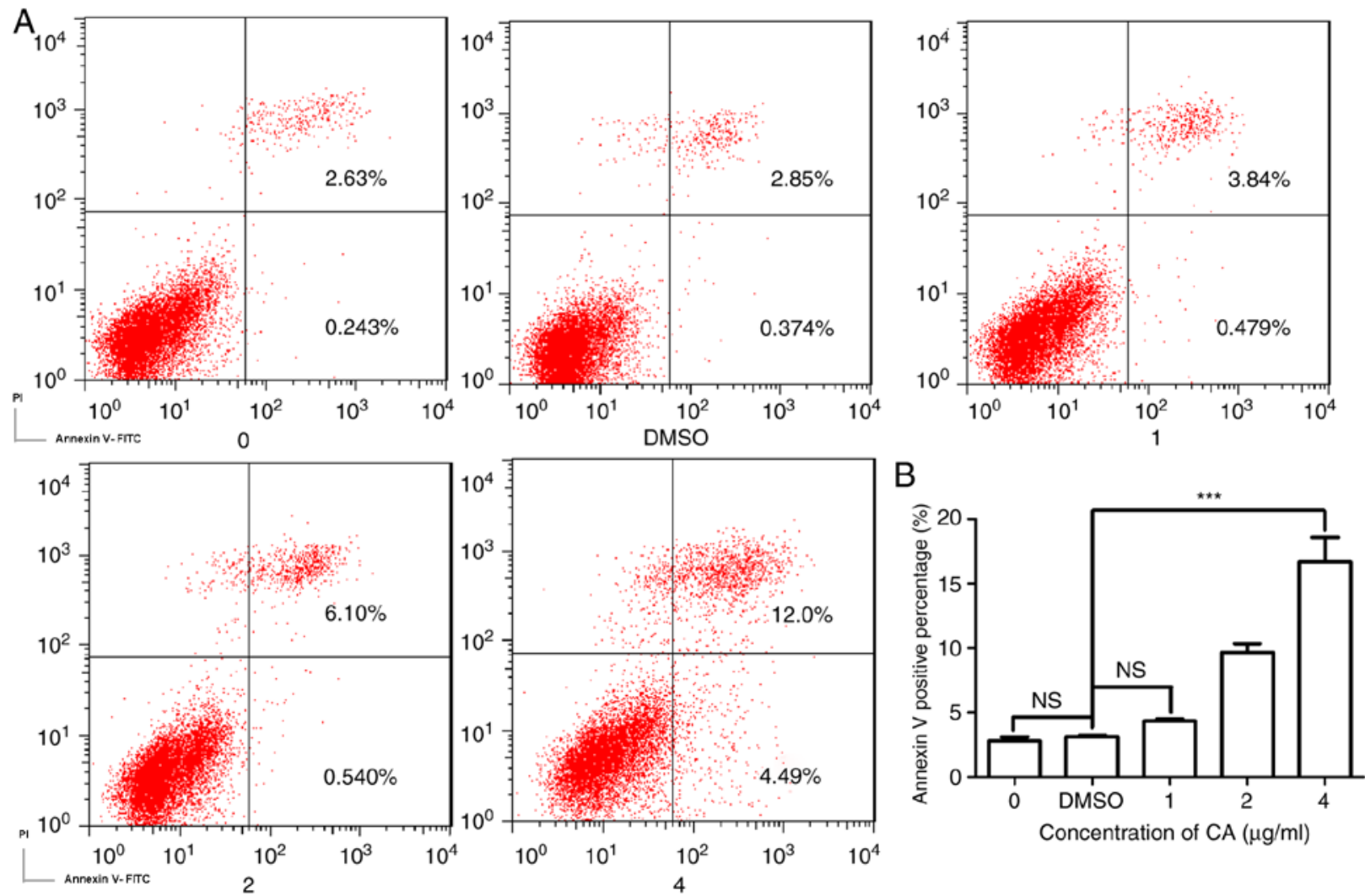

Figure 3. CA induced apoptosis in MDSCs in a dose-dependent manner. Adherent splenocytes were treated with different concentrations of CA (0, 1,2 and $4 \mu \mathrm{g} / \mathrm{ml})$ and DMSO for $48 \mathrm{~h}$ and then were stained with Annexin V-FITC and PI $(20 \mu \mathrm{g} / \mathrm{ml})$. (A) The stained cells were analyzed with a flow cytometer. (B) Bar chart demonstrating the percentages of apoptotic cells. ${ }^{* * *} \mathrm{P}<0.001$. CA, cinnamaldehyde; NS, not significant; OD, optical density.

the present study investigated the mechanism underlying this decrease in cell viability. Fig. 3A is a typical quadrant analysis of the adherent splenocytes isolated from the mice bearing CT26 tumors, treated with CA at different concentrations for $48 \mathrm{~h}$, double stained with Annexin V-FITC/PI and subjected to flow cytometry. The percentage of cells in early apoptosis increased from 0.243 to $4.49 \%(4 \mu \mathrm{g} / \mathrm{ml})$. This result demonstrates that the incubation with $\mathrm{CA}$ promoted apoptosis in MDSCs in a dose-dependent manner (Fig. 3B).
CA regulates the expression of apoptosis-associated proteins. Apoptosis is classified into two categories depending on its mediation by the sequential activation of different caspase proteins (16). The present study investigated expression levels of various proteins involved in the intrinsic and extrinsic apoptosis pathways by western blotting. Caspase- 9 and caspase- 3 were activated by CA, as shown in Fig. 4A-C by a significant time-dependent increase $(\mathrm{P}<0.05)$, while the expression of p53 was also increased. 


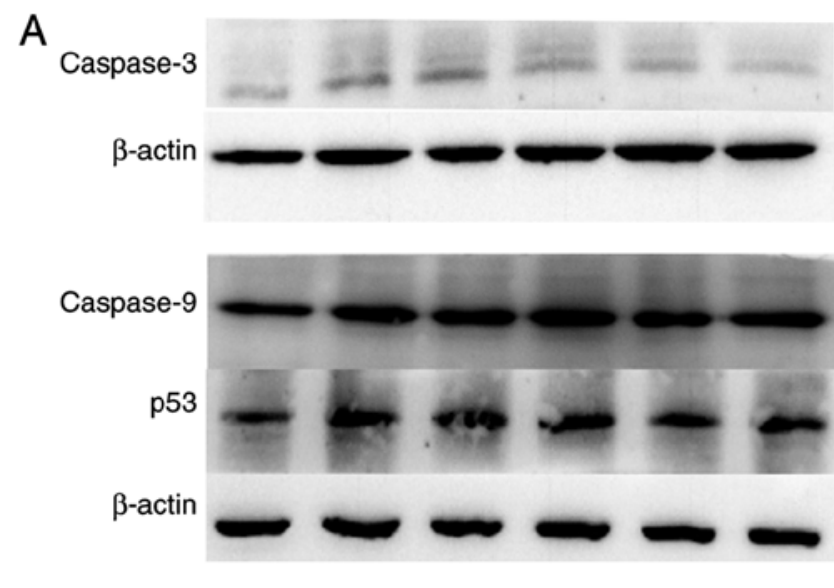

B

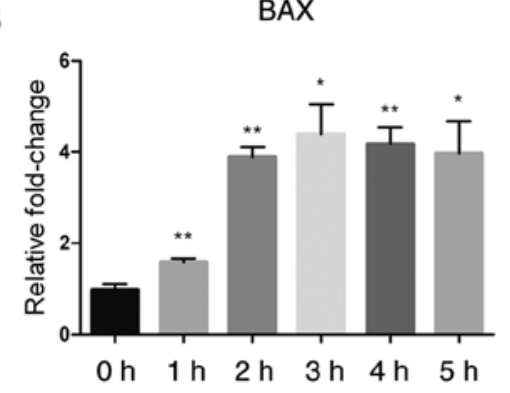

P53

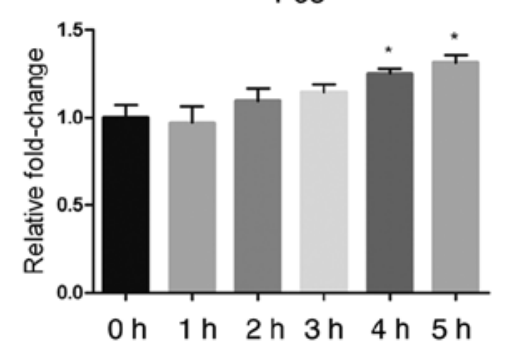

C

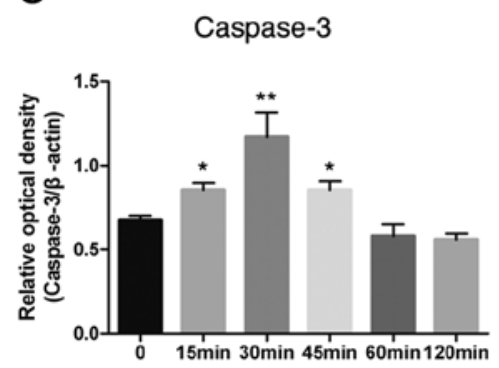

Caspase-9

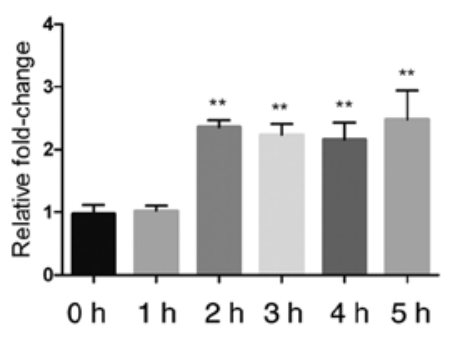

Caspase-8

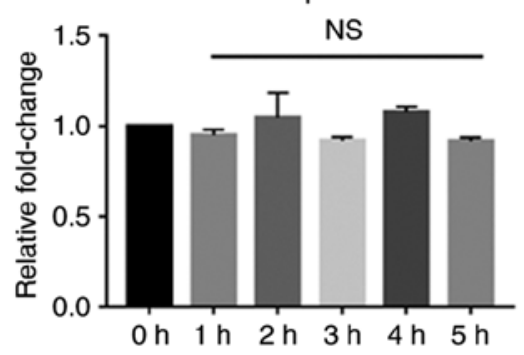

Caspase-9

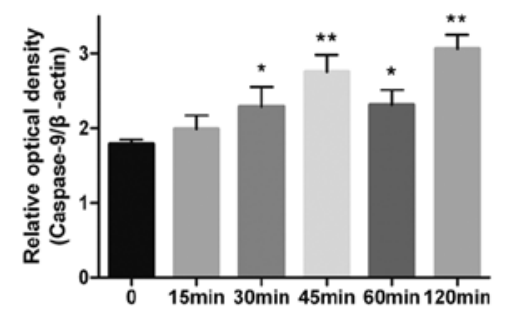

Caspase-3
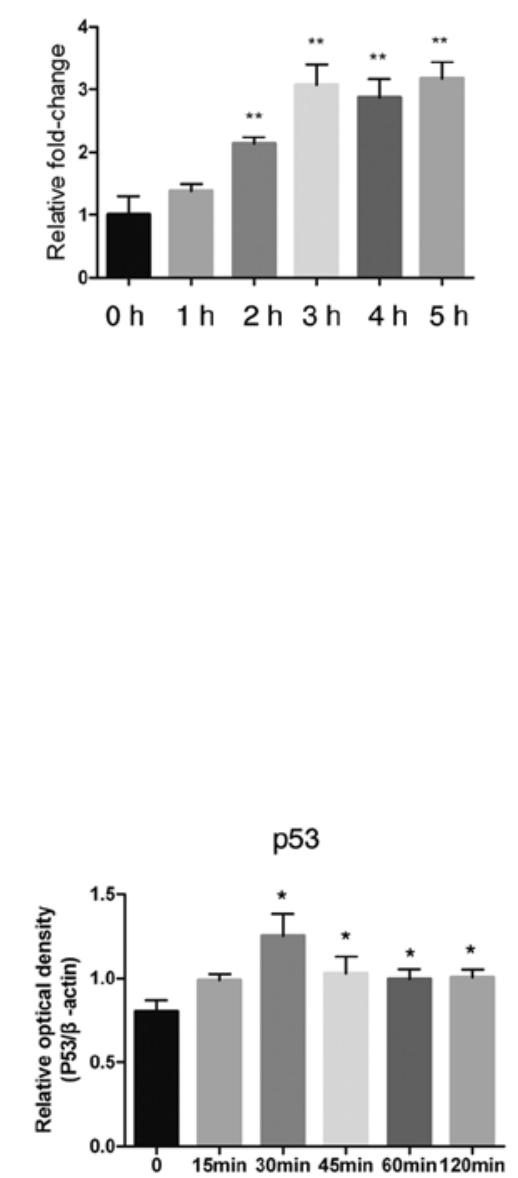

Figure 4. Expression levels of apoptosis-associated proteins changed after treatment with CA. Adherent splenocytes from mice bearing CT26 tumors were treated with CA $(4 \mu \mathrm{g} / \mathrm{ml})$ for different durations as indicated. (A) Levels of caspase- 9 , caspase-3 and p53, in total cell lysates, were determined by western blotting. The expression of $\beta$-actin served as a control. Lanes 1-6: 0, 15, 30, 45, 60 and 120 min. (B) The Bax, caspase-9, caspase-3, p53 and caspase- 8 mRNA levels were analyzed by RT-qPCR. The mRNA level of each gene was normalized to $\beta$-actin and presented as a fold increase compared with the control. (C) Clinx software to analyze the relative optical density of caspase-3, caspase-9 and p53 compared with $\beta$-actin. ${ }^{*} \mathrm{P}<0.05$ and ${ }^{* *} \mathrm{P}<0.01$. RT-qPCR, reverse transcription-quantitative polymerase chain reaction; NS, not significant; CA, cinnamaldehyde.

A series of semi-quantitative and quantitative real-time RT-PCR assays were performed on MSC-2 cells treated with CA ( $4 \mu \mathrm{g} / \mathrm{ml}$ for different periods of time). The expression levels of apoptosis factors caspase-9, caspase-3 and Bax increased in a time-dependent manner. p53 also increased slightly (Fig. 4B). These results indicated that CA induced apoptosis in MDSCs via the intrinsic pathway.
Anti-MDSC activity of CA is TLR4-dependent. To further clarify the mechanism by which extracellular CA promotes the intrinsic apoptosis pathway, splenocytes were isolated from $\mathrm{TLR}^{-/-}$mice with colon tumors. As shown in Fig. 5A and B, in TLR4 $4^{-/}$mice, CA does not decrease the percentage of MDSCs unlike its effect in WT mice (Fig. 1B). The anti-MDSC activity of CA was abolished in these cells 

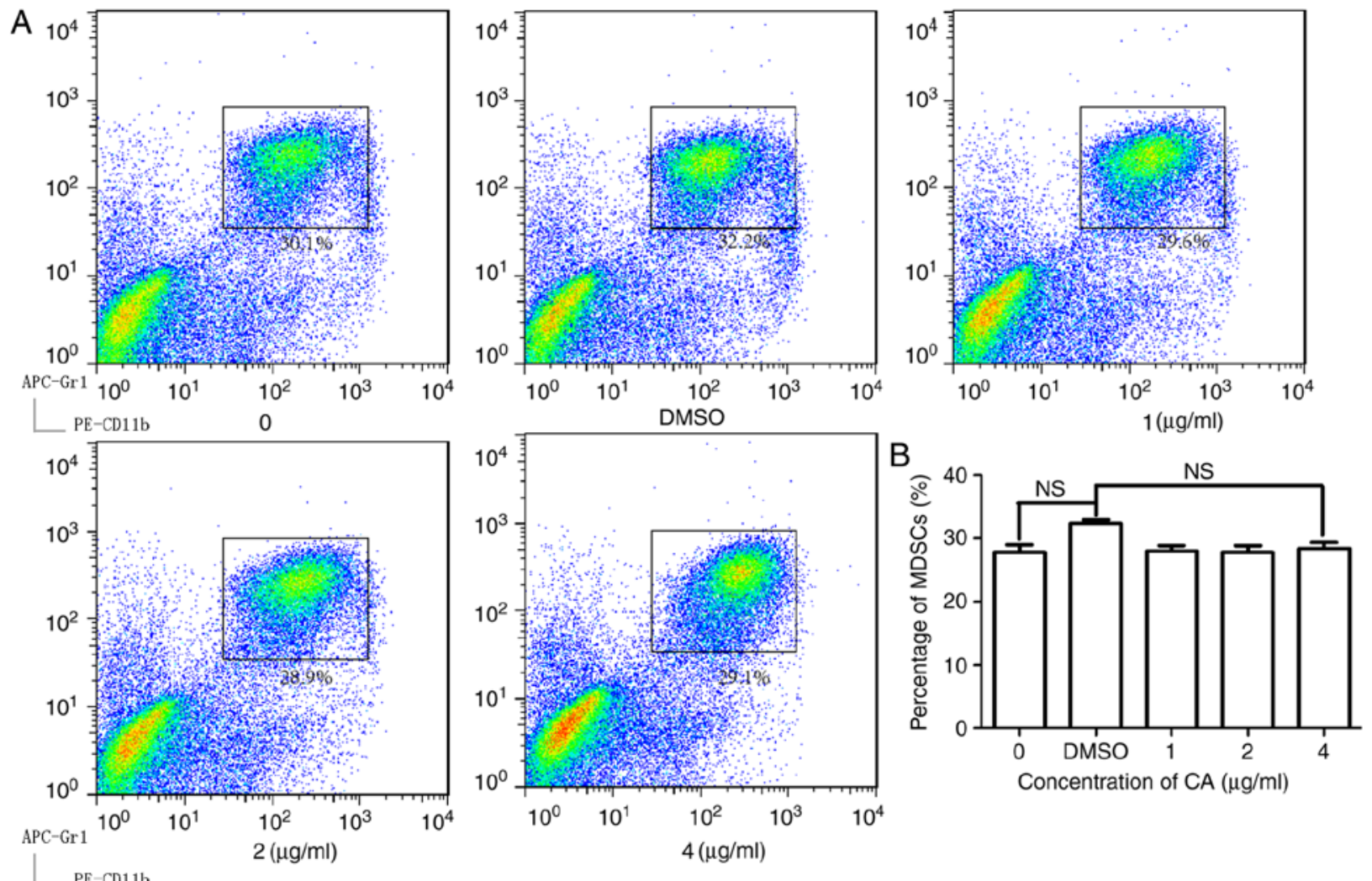

Figure 5. Anti-MDSC activity of CA is TLR4-dependent. The cells isolated from the spleens of TLR4 ${ }^{-/}$mice bearing MC38 tumors were seeded in a 96-well microplate $\left(1 \times 10^{6}\right.$ cells/well). Following treatment with different concentrations $(0,1,2$ and $4 \mu \mathrm{g} / \mathrm{ml})$ of CA and DMSO for $36 \mathrm{~h}$, the cells were stained with fluorescent antibodies and subjected to fluorescence-activated cell sorting analysis on a flow cytometer. (A) The data were analyzed using FlowJo 7.6 (B), and a bar chart was generated with GraphPad Prism 5.0. The data are expressed as the means \pm SD $(n=4)$, and the significance was determined by one-way ANOVA. CA, cinnamaldehyde; DMSO, dimethyl sulfoxide; NS, not significant.

(Fig. 5A and B), suggesting that CA reduced MDSCs through a TLR4-dependent pathway.

\section{Discussion}

There are two major strategies for reducing the cancer burden: Active prevention and early therapeutic intervention (17). Traditional Chinese medicine has been used to treat human illnesses as part of Chinese phytotherapy for thousands of years. It has been indicated that Traditional Chinese Medicine-based treatments may prevent tumorigenesis, or stabilize tumors and reduce tumor recurrence and metastasis (18). The present study aimed to investigate whether CA could inhibit MDSC function. CA has attracted a great deal of attention for its anticancer properties and has been demonstrated to inhibit growth and induce apoptosis in cancer cells as a naturally bioactive substance in a number of studies $(12,19,20)$. Its potential in the development of an effective anticancer and chemopreventive agent has been proven in those studies. MDSCs promote oncogenesis and metastasis by escaping immunity by inhibiting T-cell proliferation (21). The present study demonstrated that CA could selectively decrease the percentage of MDSCs in the spleens of mice with tumors. Apoptosis serves an important role in physiological development, homeostasis and pathological inflammation, infection and tumorigenesis (22-24). The detection of apoptosis in MDSCs by staining with Annexin V-FITC/PI in the present study revealed a significant increase in the percentage of apoptotic MDSCs following treatment with CA. The levels of caspase-9 and caspase-3, as measured by western blotting, were increased in a time-dependent manner when the MDSCs were treated with $\mathrm{CA}$, suggesting that CA promotes apoptosis in MDSCs via the intrinsic pathway, which is an important type of apoptosis initiated by the activation of specific receptors.

The p53 protein is an important factor in numerous processes, such as regulating the repair of cellular DNA, inducing apoptosis, inhibiting angiogenesis and inducing oxidative shock (25). In the present study, the expression of p53 increased in a time-dependent manner in MDSCs, following exposure to CA ( $4 \mu \mathrm{g} / \mathrm{ml})$ for $5 \mathrm{~h}$, supporting the evidence that $\mathrm{CA}$ induces apoptosis via the activation of $\mathrm{p} 53$. This research demonstrated that CA could not decrease the ratio of MDSCs in the spleens of TLR4-knockout mice with colon tumors after the cells were exposed to CA (Fig. 5A and B), suggesting that the apoptosis process is initiated by TLR4.

In conclusion, the results of the present study demonstrated that CA could selectively decrease the percentage of MDSCs in the spleens of mice with tumors by promoting apoptosis in MDSCs, thereby elucidating another facet of its antitumor properties.

\section{Acknowledgements}

The authors would like to thank Miss Mei Jie (Institute of Biophysics, Chinese Academy of Sciences, Beijing, China) for providing the cell culture. 


\section{Funding}

This study was supported by the Zhejiang Province Natural Science Foundation (grant no. LY15H160003).

\section{Availability of data and materials}

All data generated or analyzed during this study are included in this published article.

\section{Authors' contributions}

$\mathrm{NT}$ and $\mathrm{CL}$ conceived and designed the experiments. WH, WZ, YW, QZ and ZW performed the experiments. WZ, QZ, YW, MH and FM analyzed the data. WH, NT and CL wrote the paper. All authors read and approved the final manuscript.

\section{Ethics approval and consent to participate}

Animal experiments were approved by the Biological Research Ethics Committee (Institute of Biophysics, Chinese Academy of Sciences, Beijing, China).

\section{Patient consent for publication}

Not applicable.

\section{Competing interests}

The authors declare that they have no competing interests.

\section{References}

1. Gabrilovich DI and Nagaraj S: Myeloid-derived suppressor cells as regulators of the immune system. Nat Rev Immunol 9: 162-174, 2009.

2. Bingisser RM, Tilbrook PA, Holt PG and Kees UR: Macrophage-derived nitric oxide regulates $\mathrm{T}$ cell activation via reversible disruption of the Jak3/STAT5 signaling pathway. J Immunol 160: 5729-5734, 1998.

3. Harari O and Liao JK: Inhibition of MHC II gene transcription by nitric oxide and antioxidants. Curr Pharm Des 10: 893-898, 2004.

4. Rivoltini L, CarrabbaM,Huber V,Castelli C,NovellinoL, DalerbaP, Mortarini R, Arancia G, Anichini A, Fais S and Parmiani G: Immunity to cancer: Attack and escape in T lymphocyte-tumor cell interaction. Immunol Rev 188: 97-113, 2002.

5. Baniyash M: Myeloid-derived suppressor cells as intruders and targets: Clinical implications in cancer therapy. Cancer Immunol Immunother 65: 857-867, 2016.

6. Long AH,Highfill SL, Cui Y, Smith JP, Walker AJ, Ramakrishna S, El-Etriby R, Galli S, Tsokos MG, Orentas RJ and Mackall CL: Reduction of MDSCs with all-trans retinoic acid improves CAR therapy efficacy for sarcomas. Cancer Immunol Res 4: 869-880, 2016.

7. Waldron TJ, Quatromoni JG, Karakasheva TA, Singhal S and Rustgi AK: Myeloid derived suppressor cells: Targets for therapy. Oncoimmunology 2: e24117, 2013.

8. Tsai KD, Liu YH, Chen TW, Yang SM, Wong HY, Cherng J, Chou KS and Cherng JM: Cuminaldehyde from Cinnamomum verum induces cell death through targeting topoisomerase 1 and 2 in human colorectal adenocarcinoma COLO 205 cells. Nutrients 8: pii: E318, 2016.
9. Matan N, Rimkeeree H, Mawson AJ, Chompreeda P, Haruthaithanasan V and Parker M: Antimicrobial activity of cinnamon and clove oils under modified atmosphere conditions. Int J Food Microbiol 107: 180-185, 2006.

10. Kim DH, Kim CH, Kim MS, Kim JY, Jung KJ, Chung JH, An WG, Lee JW, Yu BP and Chung HY: Suppression of age-related inflammatory NF-kappaB activation by cinnamaldehyde. Biogerontology 8: 545-554, 2007.

11. Singh G, Maurya S, DeLampasona MP and Catalan CA: A comparison of chemical, antioxidant and antimicrobial studies of cinnamon leaf and bark volatile oils, oleoresins and their constituents. Food Chem Toxicol 45: 1650-1661, 2007.

12. Koppikar SJ, Choudhari AS, Suryavanshi SA, Kumari S, Chattopadhyay S and Kaul-Ghanekar R: Aqueous cinnamon extract (ACE-c) from the bark of Cinnamomum cassia causes apoptosis in human cervical cancer cell line $(\mathrm{SiHa})$ through loss of mitochondrial membrane potential. BMC Cancer 10: 210, 2010.

13. Wong HY, Tsai KD, Liu YH, Yang SM, Chen TW, Cherng J, Chou KS, Chang CM, Yao BT and Cherng JM: Cinnamomum verum component 2-methoxycinnamaldehyde: A novel anticancer agent with both anti-topoisomerase I and II activities in human lung adenocarcinoma A549 cells in vitro and in vivo. Phytother Res 30: 331-340, 2016.

14. Kwon HK, Hwang JS, So JS, Lee CG, Sahoo A, Ryu JH, Jeon WK, Ko BS, Im CR, Lee SH, et al: Cinnamon extract induces tumor cell death through inhibition of NFkappaB and AP1. BMC Cancer 10: 392, 2010.

15. Livak KJ and Schmittgen TD: Analysis of relative gene expression data using real-time quantitative PCR and the 2(-Delta Delta C(T)) method. Methods 25: 402-408, 2001.

16. Nagata $S$ and Tanaka M: Programmed cell death and the immune system. Nat Rev Immunol 17: 333-340, 2017.

17. Elmore S: Apoptosis: A review of programmed cell death. Toxicol Pathol 35: 495-516, 2007

18. Wang CY, Bai XY and Wang CH: Traditional Chinese medicine: A treasured natural resource of anticancer drug research and development. Am J Chin Med 42: 543-559, 2014.

19. Kwon HK, Jeon WK, Hwang JS, Lee CG, So JS, Park JA, Ko BS and Im SH: Cinnamon extract suppresses tumor progression by modulating angiogenesis and the effector function of $\mathrm{CD} 8^{+}$ T cells. Cancer Lett 278: 174-182, 2009.

20. Hong SH, Ismail IA, Kang SM, Han DC and Kwon BM: Cinnamaldehydes in cancer chemotherapy. Phytother Res 30: 754-767, 2016.

21. Veglia F, Perego M and Gabrilovich D: Myeloid-derived suppressor cells coming of age. Nat Immunol 19: 108-119, 2018.

22. Youn JI, Nagaraj S, Collazo M and Gabrilovich DI: Subsets of myeloid-derived suppressor cells in tumor-bearing mice. J Immunol 181: 5791-5802, 2008.

23. Wu MH, Jin XK, Yu AQ, Zhu YT, Li D, Li WW and Wang Q: Caspase-mediated apoptosis in crustaceans: Cloning and functional characterization of EsCaspase-3-like protein from Eriocheir. Fish Shellfish Immunol 41: 625-632, 2014.

24. Kumar S: Caspase function in programmed cell death. Cell Death Differ 14: 32-43, 2007.

25. Galluzzi L, Vitale I, Abrams JM, Alnemri ES, Baehrecke EH, Blagosklonny MV, Dawson TM, Dawson VL, El-Deiry WS, Fulda S, et al: Molecular definitions of cell death subroutines: Recommendations of the nomenclature committee on cell death 2012. Cell Death Differ 19: 107-120, 2012.

This work is licensed under a Creative Commons Attribution-NonCommercial-NoDerivatives 4.0 International (CC BY-NC-ND 4.0) License. 